University of South Florida

DIGITAL COMMONS

Digital Commons @ University of

@ UNIVERSITY OF SOUTH FLORIDA

South Florida

3-17-2005

\title{
Interannual Temperature Variability in the Tropical Pacific and Lagrangian Heat Transport Pathways
}

\author{
C. L. Holland \\ University of Texas \\ Gary T. Mitchum \\ University of South Florida, mitchum@usf.edu
}

Follow this and additional works at: https://digitalcommons.usf.edu/msc_facpub

Part of the Marine Biology Commons

\section{Scholar Commons Citation}

Holland, C. L. and Mitchum, Gary T., "Interannual Temperature Variability in the Tropical Pacific and Lagrangian Heat Transport Pathways" (2005). Marine Science Faculty Publications. 51.

https://digitalcommons.usf.edu/msc_facpub/51

This Article is brought to you for free and open access by the College of Marine Science at Digital Commons @ University of South Florida. It has been accepted for inclusion in Marine Science Faculty Publications by an authorized administrator of Digital Commons @ University of South Florida. For more information, please contact digitalcommons@usf.edu. 


\title{
Interannual temperature variability in the tropical Pacific and Lagrangian heat transport pathways
}

\author{
Christina L. Holland ${ }^{1}$ and Gary T. Mitchum \\ College of Marine Science, University of South Florida, St. Petersburg, Florida, USA \\ Received 6 May 2004; revised 3 January 2005; accepted 28 January 2005; published 17 March 2005.
}

[1] In a previous study we found that volume variability during an El Niño-Southern Oscillation (ENSO) event is well described by variations in, and redistribution of, the heat content for any given region within the tropical Pacific. In this study we use numerical model temperature and velocity fields in a Lagrangian analysis of heat content variability. These three-dimensional fields are used to examine specific warm and cool anomaly regions by computing trajectories back through time to the origins of the anomalously warm or cool water. In particular, we find that three distinct pathways are important in creating and maintaining the warm eastern equatorial anomaly, including pathways in the basin interior in both hemispheres. After this warm anomaly at peak ENSO, offequatorial anomalies form both in the eastern Pacific and in the far western Pacific. The west Pacific off-equatorial cool anomalies are attributed to ENSO variations in the Ekman pumping in those regions.

Citation: Holland, C. L., and G. T. Mitchum (2005), Interannual temperature variability in the tropical Pacific and Lagrangian heat transport pathways, J. Geophys. Res., 110, C03017, doi:10.1029/2004JC002466.

\section{Introduction}

[2] Our dynamical understanding of the coupled system we call the El Niño-Southern Oscillation, or ENSO, has been constantly evolving, ever since Bjerknes [1969] first asserted that oceanic El Niño events were linked to the Southern Oscillation of the atmosphere. This system is governed by positive feedbacks wherein the interannual scale atmospheric pressure anomalies characterized by the Southern Oscillation Index (SOI) produce anomalously warm sea surface temperature (SST) conditions in the eastern tropical Pacific, and these SST variations in turn strengthen the atmospheric anomalies.

[3] It soon became apparent that local atmospheric pressure and wind anomalies could not account for the ENSO variations in SST in the eastern equatorial Pacific. Wyrtki [1975] suggested that the wind anomalies far away in the central equatorial region are more relevant. These central equatorial wind anomalies, he argued, force equatorial Kelvin waves that propagate into the eastern tropical Pacific, pushing the thermocline deeper and bringing warmer water into the region. Schopf and Harrison [1983] showed through model simulations that this wave hypothesis could account for the observed variability, so long as certain initial conditions were met. With the understanding of the importance of wave dynamics in the system, the way was paved for an improved description of the timing of the ENSO events. Cane and Zebiak [1985] found that elevated heat content within the tropical

\footnotetext{
USA.

Copyright 2005 by the American Geophysical Union. 0148-0227/05/2004JC002466
}

${ }^{1}$ Now at Institute for Geophysics, University of Texas, Austin, Texas,
Pacific was a necessary precursor to an El Niño event, and proposed that this requirement could explain the observed irregularity of events. The delayed oscillator paradigm put forth by Schopf and Suarez [1988] explicitly connected the temporal spacing of ENSO events to the travel times of Kelvin and Rossby wave propagation across the basin. Schopf and Suarez [1990] then further refined their model to allow for the attenuation of the westward propagating Rossby waves. The original delayed oscillator required wave reflection only at the western boundary of the Pacific, but Picaut et al. [1996, 1997] stressed that reflections at the eastern boundary are also important to the dynamics, and proposed the advective-reflective oscillator model to include such effects.

[4] For a long time the delayed oscillator was the widely accepted paradigm for ENSO. In this view, and even in the later advective-reflective oscillator, the initiation and maintenance of ENSO events are controlled by actions within the equatorial wave guide, a very narrow latitude range about the equator. There is growing evidence, though, to suggest that actions at higher latitudes are important in driving ENSO. Wyrtki [1985] estimated the warm water volume variability of the tropical Pacific $\left(15^{\circ} \mathrm{S}-15^{\circ} \mathrm{N}\right)$ using data from a network of tide gauges, and concluded that this volume increased gradually prior to an El Niño event, only to fall precipitously during the event itself. He described this as ENSO "flushing" warm water out of the tropical Pacific. Mitchum [1987] suggested that off-equatorial wind anomalies, consistent with the Gill [1980] atmospheric response to equatorial heating anomalies, could increase the warm water convergence in the equatorial Pacific, so that large-scale winds could be used to form an improved ENSO index. Perigaud et al. [1997] also stress the importance of offequatorial wind anomalies on the progression of ENSO. 
[5] Incorporating the role of such off-equatorial influences has led to a shift in the ENSO paradigm. In the equatorial ocean recharge theory of Jin [1997a, 1997b], Rossby waves transport heat away from the equatorial zone, leading to negative anomalies in the zonally integrated nearequatorial sea level and thermocline depth. The western Pacific oscillator model of Weisberg and Wang [1997] further emphasizes the role of off-equatorial SST anomalies in the western Pacific. Most recently, Wang [2001] proposed a unified oscillator model, incorporating the delayed oscillator, the advective-reflective oscillator, the equatorial ocean recharge model, and the western Pacific oscillator. Different factors dominate in different ENSO events, depending on the background conditions, which explains the observed variations from one ENSO event to another.

[6] These shifts in our paradigm for ENSO inherently depend on the idea that conditions outside the near-equatorial zone (effectively, the wave guide) are important factors in the evolution of ENSO. A crucial piece of the puzzle is whether or not warm water moves out of the tropical Pacific during ENSO warm events, as was first postulated by Wyrtki [1985]. Those results were called into question when similar calculations were done using either Geosat altimetry [Miller and Cheney, 1990] or combinations of tide gauge data and numerical model fields [Springer et al., 1990]. These studies found that the volume did decrease during warm events within $5^{\circ}-8^{\circ}$ of the equator (larger than the wave guide, but still a relatively narrow band about the equator), but that this was countered to order one by a corresponding rise in volume in the northern equatorial zone, bounded on the north by $20^{\circ} \mathrm{N}$ (still within the tropical Pacific). In our previous study [Holland and Mitchum, 2003], we confirmed these results, finding that volume loss from the tropical Pacific as a whole does occur during ENSO warm events, but that this loss is small when compared to recirculation within the tropics. We described the basic two-dimensional pattern of this redistribution by computing the volume variability in and fluxes between six geographic boxes in the tropical Pacific. Further, we demonstrated that the volume variability throughout the tropical Pacific is controlled by variations in the heat content, which we defined as being proportional to the vertical integral of the temperature anomaly. Our results are consistent with the findings of Meinen and McPhaden [2000] of two primary modes of ENSO variability in warm water volume (defined as water above the $20^{\circ} \mathrm{C}$ isotherm): an "east-west tilting" mode and an "equatorial discharge-recharge" mode which redistributes warm water within the tropical Pacific between a near equatorial zone (roughly $5^{\circ} \mathrm{S}-5^{\circ} \mathrm{N}$, from Meinen and McPhaden [2000, Figure 3]) and higher latitudes, particularly to the north. Our current study extends this discussion by exploring the specific three-dimensional Lagrangian pathways of heat transport responsible for the heat content anomalies.

[7] In particular, we will use a Lagrangian analysis to explore whether meridional transport of heat occurs only near the western boundary, or whether there are basin interior windows available for such transport. Our understanding of meridional transport in the ocean is continually advancing, although many of the studies concern decadal rather than interannual processes. Schneider et al. [1999] described the tropical-subtropical connection as a thermo- cline "bridge" controlled by (1) the propagation of isopycnal depth anomalies via wave dynamics and (2) temperature advection along isopycnals. McPhaden and Zhang [2002] propose that the decadal-scale meridional overturning in the Pacific is slowing down, and has been for some time, which could have significant impacts on our understanding of the climate system. Meanwhile, the relative importance and even existence of basin interior pathways is the subject of debate.

[8] Lu and McCreary [1995] found an apparent limit to the region in which subtropical water is able to move into the equatorial circulation; the Intertropical Convergence Zone (ITCZ) is shown to act in their model as a potential vorticity barrier to equatorward flow. The Ekman pumping is a negative quantity north of the ITCZ, but its magnitude reaches a minimum (weak Ekman pumping) just on the northern edge of the ITCZ. The Ekman pumping controls the meridional to zonal transport ratio, so subtropical water approaching the ITCZ from the north is pushed westward. The subtropical water that reaches the equatorial undercurrent in the Lu and McCreary [1995] model first has to travel all the way to the western boundary.

[9] The Lu and McCreary [1995] model, though, had low vertical resolution and parameterized entrainment and detrainment processes, and thus may not well represent the real world dynamics of midlatitude subduction, vertical mixing, and near-equatorial upwelling involved in subtropical to equatorial pathways. Indeed, there is strong evidence to suggest the presence of interior communication windows. In particular, analysis of tritium in the tropical Pacific shows definite meridional convergence to the equator from both hemispheres in the basin interior [McPhaden and Fine, 1988]. This result is clearly seen in the work of McPhaden and Fine [1988, Figure 3b]. Additionally, the results of Liu [1994] and Liu et al. [1994] show a Northern Hemisphere interior pathway to the equatorial zone, although the pathways predicted by their model show a good deal of variability with changes in model parameters. Johnson and McPhaden [1999] also see an interior pathway in the Northern Hemisphere, but this question is still open. Rothstein et al. [1998] found that, while potential vorticity considerations were important in controlling the locations of equatorward transport, nevertheless the ITCZ did not form a complete barrier (in their model), and there was an interior pathway. Nonaka and Xie [2000] found little transport toward the equator in the interior North Pacific, and suggest that the passive tracer method used by previous studies may be misleading on this point. Coles and Rienecker [2001] see a strong seasonality to the Northern Hemisphere interior pathway, with stronger flow during fall and early winter. Huang and Wang [2001] find that there is subtropical-tropical communication in the interior north Pacific, but that it is much more spatially constrained than in the Southern Hemisphere. The current study and others [Zhang and Rothstein, 2000] describe potential pathways of mass and heat horizontally and vertically within the ocean. We will specifically describe the pathways of heat (and therefore volume) redistribution within the tropical Pacific during a typical ENSO event, answering questions such as (1) whether interior pathways to the equator can exist in both hemispheres on interannual (ENSO) timescales, (2) what is the contribution of each pathway, and (3) what dynamics are responsible 
for the redistribution of heat observed during ENSO events.

[10] Our previous study [Holland and Mitchum, 2003] described the volume and heat content variability of the tropical Pacific from the Eulerian point of view. This is useful for describing the basic patterns of volume redistribution, at least in a vertically integrated sense. Now, though, we wish to delve into the three-dimensional characteristics of the temperature anomalies. We will examine the vertical profiles of the anomalies, and ask where these came from and how they were formed. It is natural at this point to switch to a Lagrangian viewpoint. This allows us to consider any parcel of water that is anomalously warm or cold during the ENSO cycle, and to trace it back through time to see where it originated and how it has been warmed or cooled along the way.

[11] The remainder of this paper will be organized as follows. The second section explains the methodology, discussing specifically the numerical model, the Lagrangian trajectory analysis, the composite ENSO event used, tests to our method, and the diagnostic terms used to describe the mechanisms leading to the warm and cold anomaly regions. The third section will present the results of our analysis, specifically for the eastern equatorial warm anomaly at peak ENSO, the off-equatorial warming in the eastern Pacific, and the cool anomalies in the west Pacific warm pool region. Following that will be a general discussion, and finally a summary of the study, with our conclusions.

\section{Methods}

\subsection{Model}

[12] In order to describe the three-dimensional pathways of heat transport, we need fairly complete and finely resolved fields of velocity and temperature, as functions of time as well as zonal, meridional, and vertical position. Such a data set does not exist observationally, so we turn to numerical simulations. The model we use is based on the Gent and Cane [1989] sigma-coordinate model, a reduced gravity, primitive equation model in which velocity, temperature, and salinity are computed within 20 vertical layers. The thickness of the mixed layer is explicitly computed, while the thicknesses of the lower layers are held to be proportional to one another according to the preset values of the sigma coordinates for each layer. This model has been modified extensively over the years. We are using a version that has been coupled to an atmospheric mixed layer model [Murtugudde et al., 1996; Seager and Murtugudde, 1997]. The effects of salinity and freshwater flux at the sea surface have been added [Murtugudde and Busalacchi, 1998]. Finally, vertical mixing is now dealt with in a hybrid mixing scheme [Chen et al., 1994], that incorporates the effects of wind stirring, shear instability, and convective overturning. We are running the model over the Pacific from $45^{\circ} \mathrm{S}$ to $45^{\circ} \mathrm{N}$. The eastern and western boundaries are realistic coastlines. The northern and southern boundaries include $10^{\circ}$ wide sponge layers. The model grid we use has $1^{\circ}$ resolution zonally and a variable meridional resolution (maximum at the boundaries and down to one third of a degree near the equator). Surface winds are monthly fields from the National Centers for Environmental Prediction (NCEP), and the solar heating is from the
European Centre for Medium Range Weather Forecasts (ECMWF) climatology. The reliability of the model results can be assessed by comparing the volume computed by areally integrating sea level over geographic regions from the model output to volume time series computed in the same fashion from TOPEX/Poseidon altimetry. This was done for a variety of latitude ranges within the tropical Pacific, and the resulting time series were well correlated on interannual timescales [Holland and Mitchum, 2003].

\subsection{Lagrangian Trajectory Analysis}

[13] Lagrangian techniques have been used by Izumo et al. [2002] and Fukimori et al. [2004] to study ENSO variability. Izumo et al. [2002] computed trajectories of particles in a three-dimensional simulated flow field, much as we do here. In this manner, they describe the $1998 \mathrm{La}$ Niña event, finding that the cool anomaly was the result of transport only via the western boundary, with no contribution from interior pathways in either hemisphere. Fukumori et al. [2004] used a very large set of forward and adjoint passive tracers to describe the origin of the Niño-3 water. They found interior pathways in both hemispheres. Our method for computing Lagrangian trajectories is described below.

[14] Ideally, given a start position $\tilde{x}_{0}$ at time $t_{0}$, the new position at time $t_{1}$ would be computed from $\tilde{u}_{0}$, the model velocity fields of $\tilde{u}$ at the start location and time:

$$
\tilde{x}_{1}=\tilde{x}_{0}+\int_{t_{0}}^{t_{1}} \tilde{u} d t,
$$

where the integrals are taken along the path. If the time step is small, this can be written as

$$
\tilde{x}_{1}=\tilde{x}_{0}+\left(t_{1}-t_{0}\right) \tilde{u}\left(\tilde{x}_{0}, t_{0}\right)
$$

in finite difference form. These velocity fields can be linearly interpolated to the start time and position of interest, here $t_{0}$ and $\tilde{x}_{0}$. However, a problem arises with the vertical portion of (1) and (2). In the Gent and Cane [1989] model the vertical velocity, $w$, is diagnostic rather than prognostic. At each time step in the model, the horizontal divergence and the sigma coefficients are used to update the layer thicknesses, and the vertical velocities are then determined from the continuity equation within each layer. Thus computing $\mathrm{w}$ at each layer interface involves taking horizontal derivatives of the transports within the layer. This is problematic due to the Shapiro filter imposed by the model for stability. When the model's diagnostic w fields were used, trajectories that entered the near-equatorial or western boundary regions where the flows are strong were found to behave unrealistically, due to unrealistically large vertical velocity components.

[15] There is a solution, however. The model also enforces a temperature balance

$$
\frac{D T}{D t}=\frac{\partial q}{\partial z},
$$

where for simplicity we are using

$$
q=\frac{1}{\rho_{0} c_{p}} Q,
$$




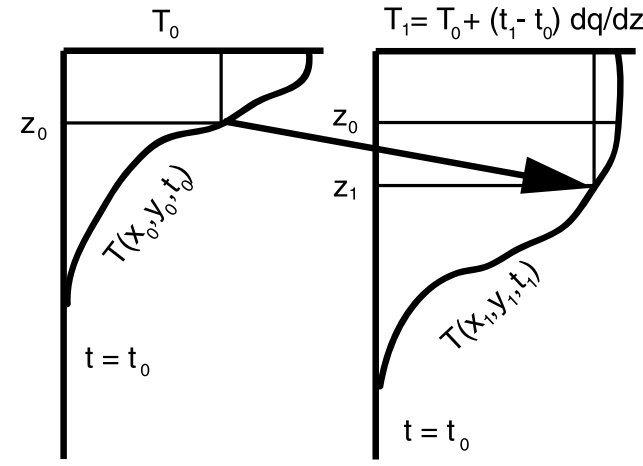

Figure 1. Schematic showing the method used to compute the vertical position of the trajectories based on the vertical temperature profiles.

and $T, \rho_{0}, c_{p}$, and $Q$ are the temperature, the density, the specific heat of water, and the vertical heat flux, respectively.

[16] The temperature of any given water parcel remains constant, unless it is heated or cooled by the vertical heat flux. We can imagine a parcel, at time $t_{0}$ and position $\tilde{x}_{0}$, which has a temperature $T_{0}$. After a time step, at time $t_{1}$, it has moved to a new horizontal position $\left(x_{1}, y_{1}\right)$. If it has not been heated or cooled, then its temperature remains at $T_{0}$, and its new vertical position, $z_{1}$, can be inferred from the model's vertical profile of temperature at the new time and horizontal position:

$$
T_{0}=T\left(x_{1}, y_{1}, z_{1}, t_{1}\right)
$$

in which $z_{1}$ is the only unknown. If the parcel has been heated or cooled between times $t_{0}$ and $t_{1}$, then its new temperature is

$$
T_{1}=T_{0}+\int_{t_{0}}^{t_{1}} \frac{\partial q}{\partial z} d t
$$

and this can be written as

$$
T_{1}=T_{0}+\left(t_{1}-t_{0}\right) \frac{\partial q}{\partial z}\left(x_{0}, y_{0}, z_{0}, t_{0}\right)
$$

if the time step is sufficiently short. The vertical position $z_{1}$ can be inferred from the relation

$$
T_{1}=T\left(x_{1}, y_{1}, z_{1}, t_{1}\right),
$$

which is analogous to (5). This method is illustrated graphically in Figure 1. Using this method, the trajectories are computed backward in time with a fourth-order RungeKutta iteration scheme.

[17] Simply computing the trajectories, via the method described above, is not enough without a way to interpret their meaning. We need a method to examine where any specific anomalous water parcel originates, the path it travels, and when and how it is heated or cooled along the way. We are interested in how the water parcel characteristics and pathway differ during ENSO conditions as compared to normal, or NULL, conditions. Trajectories will therefore computed under both NULL and ENSO conditions. In the following section, we will discuss how the NULL and ENSO composites were formed, and then the method for diagnosing the dynamics behind the trajectories will be explained.

\subsection{Composite El Niño-Southern Oscillation (ENSO) Event}

[18] There is a great deal of variability between any two ENSO events. This is due in part to differences in the underlying dynamics, as explained in the unified oscillator model of Wang [2001]. As such, it may be that the pathways of heat transport responsible for volume redistribution also vary from one event to another. The current paper asks what are the pathways for a typical ENSO event, postponing for the moment the question of inter-event differences, but this should definitely be considered in future work on this problem. We define a "typical" event by computing a composite from four particular ENSO events: 1972-1973, 1982-1983, 1986-1987, and 1997-1998, which had particularly strong SOI signatures.

[19] The method used to compute the composite is the same as described by Holland and Mitchum [2003], but is discussed briefly here. For each of the four ENSO periods, time series of velocity, $u(x, y, z, t)$ and $v(x, y, z, t)$, temperature $T(x, y, z, t)$, and vertical heat flux at the sea surface $Q(x, y, t)$ were extracted for a 72 month period, centered on the time of minimum SOI. These time series were averaged over the four events for each variable and each spatial point. The result is a set of composite fields, 72 months in length. The minimum SOI tends to align closely with the peak warming in the eastern equatorial Pacific, so this warming occurs near the center of the composite time period, at month 37 . No artificial weighting is used in the averaging, so the largest contribution to the composite is from the strongest ENSO event, in 19971998. In fact, we have computed trajectories for the primary anomaly features of the 1997-1998 event, and they are quite similar in many ways to those we will describe here from the composite. This method can certainly be used in the future to examine the important pathways and dynamics of any specific event and to explore the differences between ENSO events. We also computed a set of non-ENSO (NULL) composites in a similar manner, using four periods of relatively normal SOI, to allow us to see how ENSO trajectories differ from trajectories under normal conditions.

\subsection{Tests of the Trajectory Method}

[20] As noted by Fukimori et al. [2004], the Lagrangian method has some inherent difficulties. In particular, small perturbations in the positions at the beginning of the trajectory computation may lead to very different trajectories. Such trajectory dispersion would make this type of analysis unstable. As will be discussed, we did group similar trajectories together to describe basic pathways of redistribution. In addition, we did an explicit check of the dispersion of the trajectories, by starting with a Gaussian cluster of initial points, and tracking them back in time. The Gaussian clump began with a mean position of $x=119^{\circ} \mathrm{W}$, $y=0^{\circ}, z=-50 \mathrm{~m}$ (within the eastern equatorial warm anomaly), and standard deviations of $0.25^{\circ}, 0.0875^{\circ}$, and 
$2 \mathrm{~m}$ in the zonal, meridional, and vertical directions, respectively. Trajectories were then computed backward in time, using the method described in this paper, for 16 months. There was some limited dispersion (separation) of the trajectories as the computation progressed, but they remained visibly cohesive for the entire run. The standard deviations of the "initial" positions, 16 months back from the start time, were $4.6^{\circ}, 0.43^{\circ}$, and $3.6 \mathrm{~m}$ in the zonal, meridional, and vertical directions. The trajectories were all similar, following the same pathway in all three dimensions. This result gives us confidence that our method is providing reliable trajectories that are not sensitive to small differences in location.

[21] Another issue is the temporal resolution. Forming a composite ENSO event requires a multidecadal model run. The time step of the model is one hour, but keeping output from every time step quickly becomes impractical for such a long model run. We have set the model to output snapshots of layer thickness, temperature, and salinity once every model month. At the same time, average values of the horizontal fluxes are computed and output every month. The averages of the fluxes are carefully computed such that the model continuity, momentum, temperature, and salt balances are exactly met, except for the effect of horizontal model smoothing. This combination of temporal snapshots of state variables and averages of fluxes is essential to conserving mass, momentum, energy, and salt. In addition, this provides everything needed to compute the trajectories.

[22] The question also arises whether the temporal resolution of the model fields used has any significant impact on the computed trajectories. Using monthly fields to compute trajectories with daily resolution requires linear interpolation of the model $T, u, v$, and $Q$ fields. We tested the effect of this by completing a relatively short (1 year) model run with daily output, and then computing two sets of year-long trajectories, using daily and monthly model fields. The trajectories in each case have a temporal resolution of one day. The two trajectory sets are quite similar, although not identical. The same source regions, depths, and pathways are important in both cases. This indicates that linear interpolation from the monthly average fluxes does a good job of capturing the net translation of a water parcel over a month's time. We conclude that the temporal resolution of the model output and the linear interpolation of those model fields are not critical factors in this method. All of the results discussed from here on will be based on the monthly output fields.

\subsection{Diagnostic Terms}

[23] Once the composite fields are generated and the trajectories are computed, we can diagnose the dynamics that vary between the NULL case and the ENSO case by defining a set of diagnostic terms. For that purpose, it is necessary to examine the equation for the heat content evolution of a parcel at location $\tilde{x}_{0}$ at time $t_{0}$, spanning a depth range $\Delta z$ centered on $z_{0}$. This is approximately proportional to

$$
\Delta \Theta \approx\left[T_{E}\left(\tilde{x}_{0}, t_{0}\right)-T_{N}\left(\tilde{x}_{0}, t_{0}\right)\right] \Delta z,
$$

where the $E$ and $N$ subscripts denote ENSO and NULL conditions, respectively. This anomaly can be expressed in terms of the temperature at some earlier time $t_{\text {init }}$ along the ENSO and NULL trajectories, $\tilde{x}_{E}$ and $\tilde{x}_{N}$, respectively, the spatial displacement between the two trajectories, and the heating or cooling in each case. The anomaly at location $\tilde{x}_{0}$ and time $t_{0}$ is

$$
\begin{aligned}
\Delta \Theta \approx & {\left[T_{E}\left(\tilde{x}_{E}, t_{\text {init }}\right)-T_{N}\left(\tilde{x}_{N}, t_{\text {init }}\right)\right] \Delta z } \\
& +\left\{\left[\int_{t_{\text {init }}}^{t_{0}} \frac{\partial q_{E}}{\partial z} d t\right]_{E}-\left[\int_{t_{\text {init }}}^{t_{0}} \frac{\partial q_{N}}{\partial z} d t\right]_{N}\right\} \Delta z .
\end{aligned}
$$

Note that in (10) the subscripts $N$ and $E$ again mean the NULL and ENSO cases. Specifically, $T_{N}, T_{E}, q_{N}$, and $q_{E}$ refer to the temperature and vertical heat fluxes during NULL and ENSO time periods, while $\tilde{x}_{N}, \tilde{x}_{E}$, and anything in square brackets like []$_{N}$ or []$_{E}$ refer to properties along the NULL or ENSO pathways or at the NULL or ENSO points of origin. This convention will be used throughout the rest of this paper.

[24] The first term in (10) combines the effect of the temporal differences between the $T_{N}$ and $T_{E}$ fields and the effect of the different points of origin, $\tilde{x}_{N}$ and $\tilde{x}_{E}$. These can be separated by considering the normal temperature at the ENSO start position, $T_{N}\left(\tilde{x}_{E}, t_{\text {init }}\right)$. The second term in (10) can also be separated into two parts by considering the integrated effect the normal or NULL heating $\left(q_{N}\right)$ would have along the ENSO pathway. This leads to the expression

$$
\begin{aligned}
\Delta \Theta \approx & {\left[T_{E}\left(\tilde{x}_{E}, t_{\text {init }}\right)-T_{E}\left(\tilde{x}_{N}, t_{\text {init }}\right)\right] \Delta z+\left(x_{E}-x_{N}\right)\left\langle\frac{d T_{N}}{d x}\right\rangle \Delta z } \\
& +\left(y_{E}-y_{N}\right)\left\langle\frac{d T_{N}}{d y}\right\rangle \Delta z+\left(z_{E}-z_{N}\right)\left\langle\frac{d T_{N}}{d z}\right\rangle \Delta z \\
& +\left[\int_{t_{\text {init }}}^{t_{0}} \frac{\partial q_{E}}{\partial z}-\frac{\partial q_{N}}{\partial z} d t\right]_{E} \Delta z+\left\{\left[\int_{t_{\text {tinit }}}^{t_{0}} \frac{\partial q_{N}}{\partial z} d t\right]_{E}\right. \\
& \left.-\left[\int_{t_{\text {tinit }}}^{t_{0}} \frac{\partial q_{N}}{\partial z} d t\right]_{N}\right\} \Delta z
\end{aligned}
$$

The first term on the right-hand side of (11) is the temporal effect of $T_{E}-T_{N}$ at the ENSO point of origin $\tilde{x}_{E}$, and is simply used as a stopping criterion. To diagnose the ENSO anomaly, we must integrate back to an origin point at a time when the anomaly is as close as possible to zero. The minimum in this term is used to determine how far back in time to compute the trajectories. The second, third, and fourth terms incorporate the effect the different origins, $\tilde{x}_{N}$ and $\tilde{x}_{E}$, would have if there were no temporal ENSO anomaly. This is the effect of the ENSO pathway, divided into zonal, meridional, and vertical components by computing the NULL temperature at the vertices of the virtual cube formed by all combinations of $x_{N}, x_{E}, y_{N}, y_{E}, z_{N}$, and $z_{E}$. The temperature differences along the edges of the cube provide four estimates each for the $x, y$, and $z$ components, and these are then averaged to form the $\left\langle d T_{N}\right\rangle$ $d x\rangle,\left\langle d T_{N} / d y\right\rangle$, and $\left\langle d T_{N} / d z\right\rangle$ that appear in (11). The zonal and meridional components show any difference due to the horizontal position of the pathway taken during ENSO, while the vertical component highlights the effect of anomalous upwelling or downwelling. The fifth term on 
Table 1. Summary of Diagnostic Terms

\begin{tabular}{clr}
\hline Term From Equation (12) & Expansion (From Equation (11)) & Physical Significance \\
\hline$\Delta \Theta_{1}$ & {$\left[T_{E}\left(\tilde{x}_{E}, t_{\text {init }}\right)-T_{N}\left(\tilde{x}_{E}, t_{\text {init }}\right)\right] \Delta z$} & $\begin{array}{c}\text { heat anomaly for a water parcel at the point of origin, at an initial } \\
\text { time } t_{\text {init, }} \text { chosen such that this term is minimized } \\
\text { effect of the zonal position of the water parcel from the zonal } \\
\text { gradient of temperature } \\
\text { effect of the meridional position of the water parcel from the } \\
\text { meridional gradient of temperature } \\
\text { effect of the vertical position of the water parcel from the vertical } \\
\text { gradient of temperature; shows the effect of upwelling or } \\
\text { downwelling anomalies }\end{array}$ \\
$\Delta \Theta_{3}$ & $\left(x_{E}-x_{N}\right)\left\langle\frac{d T_{N}}{d x}\right\rangle \Delta z$ & $\begin{array}{l}\left(y_{E}-y_{N}\right)\left\langle\frac{d T_{N}}{d y}\right\rangle \Delta z \\
\text { temporal effect, along the ENSO water parcel trajectory, of ENSO } \\
\text { versus NULL heating } \\
\text { difference in heating felt by a water parcel due solely to its } \\
\text { following a different pathway during ENSO than during NULL } \\
\text { conditions }\end{array}$ \\
$\Delta \Theta_{5}$ & {$\left[\int_{\text {tinit }}^{t_{0}} \frac{\partial q_{E}}{\partial z}-\frac{\partial q_{N}}{\partial z} d t\right]_{E} \quad \Delta z$} &
\end{tabular}

the right-hand side of (11) is the temporal difference in the vertical heating between ENSO and NULL conditions, and the sixth term is the difference in the heating felt by each water parcel, due to the difference in location of the NULL and ENSO pathways. The equation for the integrated heat content, equation (10), then becomes

$$
\Delta \Theta=\sum_{n=1}^{6} \Delta \Theta_{n},
$$

where all of the terms $\Delta \Theta_{n}$ used in our diagnosis are detailed for reference in Table 1.

[25] We computed trajectories for a number of horizontal locations within anomaly regions of ENSO, at $10 \mathrm{~m}$ depth intervals in the upper $1000 \mathrm{~m}$. This gives thousands of trajectories, each of which has a corresponding set of values of $\Delta \Theta_{n}$. Since it becomes much easier to examine the patterns involved if similar trajectories are grouped together, we grouped trajectories that had similar initial horizontal position, comparable ENSO and NULL pathways (they stay together horizontally and vertically), and comparable values of $\Delta \Theta_{n}$ for $n$ between 1 and 6 . Two examples of this grouping technique are shown in Figure 2.

\section{Results}

[26] Exploring the ENSO pathways of redistribution and exchange processes requires first examining the heat content as a function of time, and considering how this differs during the warm phase of ENSO (El Niño) from normal conditions. The heat content anomaly, $\Delta \Theta$, defined as the heat content difference for a water parcel between the ENSO composite and the NULL composite conditions, is caused by six dynamical factors, described in the methods section of this paper (see Table 1). This heat content anomaly can be vertically integrated, from the bottom of the deepest active model layer (the upper bound of the motionless lower layer) to the sea surface, to obtain a function of longitude, latitude, and time. When examining maps of this quantity at different times through the ENSO cycle, interesting features are readily apparent. The general criteria used to select a feature for study were that the feature is interesting if it is (1) strong (generally greater than 300 Kelvin meters $(\mathrm{K} \mathrm{m})$ ), (2) large (several degrees wide in at least one dimension), and (3) persistent (present from one month to another either in the same location or moving with reasonable propagation characteristics). The anomalous features to be discussed in this paper are shown in Figure 3. First, there is the strong warming in the eastern equatorial Pacific (within $3^{\circ}$ of the equator, between $\sim 135^{\circ} \mathrm{W}$ and the eastern boundary) at the warm peak of ENSO. Two months after that anomaly has reached peak strength in the eastern equatorial Pacific, eastern Pacific off-equatorial warm anomalies begin to form at $\sim 12^{\circ} \mathrm{N}$ and $12^{\circ} \mathrm{S}$. Another month later, strong cool anomalies form $\sim 5^{\circ}-6^{\circ}$ north
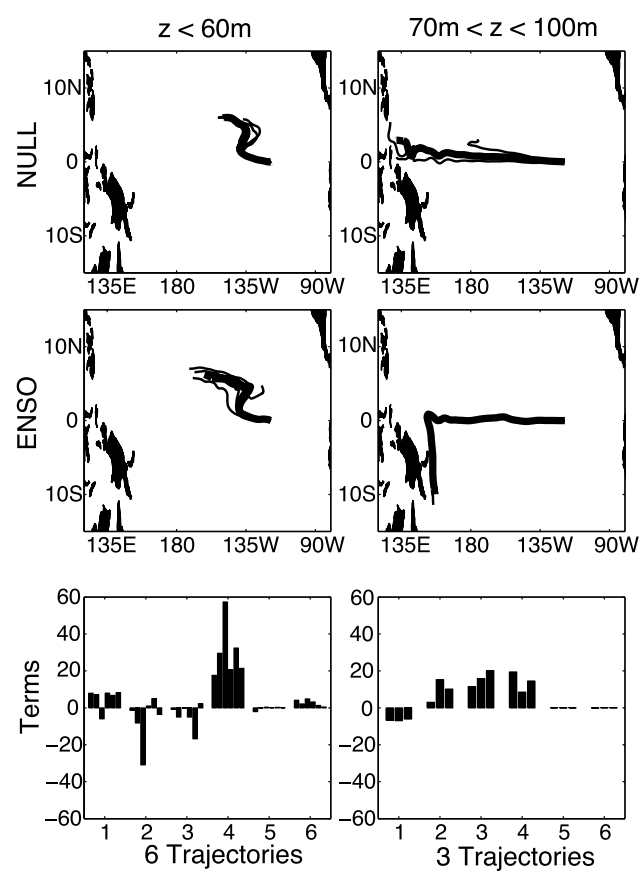

Figure 2. Examples showing how similar trajectories were grouped for analysis. The trajectories shown are for the point $119^{\circ} \mathrm{W}$ on the equator. (left) Upper $60 \mathrm{~m}$ (contains six trajectories) and (right) depth range 70-100 m (contains three trajectories). (top) NULL trajectories and (middle) El Niño-Southern Oscillation (ENSO) trajectories; the bold line in each panel is the average of the trajectories. (bottom) Size of the diagnosis terms for all of the trajectories shown. 


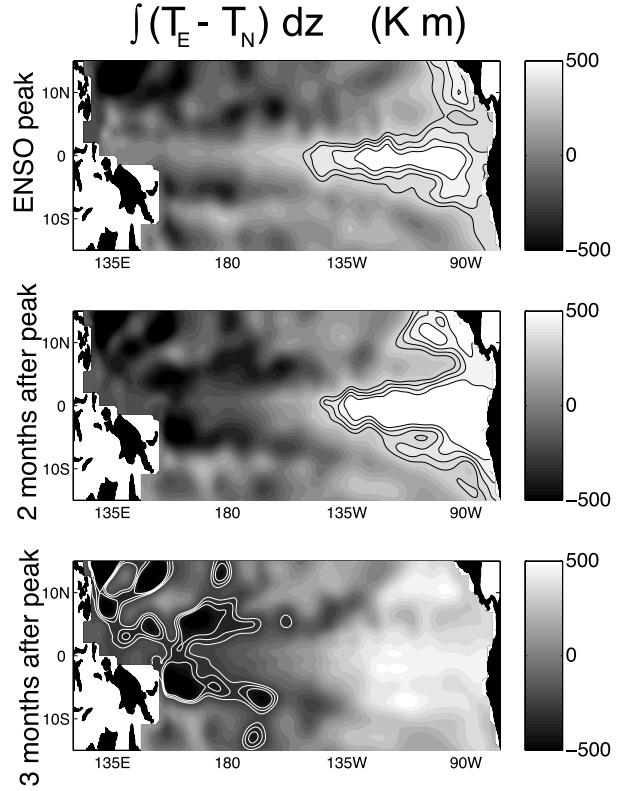

Figure 3. Maps of the vertically integrated heat anomaly at three time steps, showing the features to be discussed. (top) Heat content anomaly at the peak of the ENSO event. (middle) Two months later, when off-equatorial warm anomalies have formed at $\sim 12^{\circ} \mathrm{N}$ and $12^{\circ} \mathrm{S}$. (bottom) One month after that, by which time cool anomalies have formed in the western off-equatorial Pacific $\left(5^{\circ}-6^{\circ}\right.$ north and south). The contours are used to highlight the features, and each contour is $50 \mathrm{~K} \mathrm{~m}$ of heat content anomaly.

and south of the equator in the western Pacific. For each feature, trajectories were computed every $10 \mathrm{~m}$ in the vertical and at several points in the horizontal surrounding the maximum, and differences between the NULL and ENSO trajectories were explored to explain the anomaly.

\subsection{Eastern Equatorial Warm Anomaly at Peak ENSO}

[27] The first feature to be discussed is the warm anomaly in the eastern equatorial Pacific that occurs at peak ENSO warming (month 37 of our 6 year composite). This is the first really strong feature of an ENSO warm event, with a maximum amplitude of nearly $600 \mathrm{~K} \mathrm{~m}$. It is symptomatic of the large zonal shift during the warm phase of ENSO of volume and sea surface pressure. The anomaly is mapped in Figure 4, and it is quite similar to the same feature in a composite event shown by Cane [1983, Figure 3]. The average depth profile of the temperature anomaly is shown in Figure 4. The major portion of the heat content anomaly is due to elevated temperatures in the upper $150 \mathrm{~m}$. At any point in time, the total anomaly of all the water parcels that will be at location $\tilde{x}_{0}$ at time $t_{0}$ (the start of our trajectory computation) is the sum of our first diagnostic term, $\Delta \Theta_{1}$ (see Table 1) over that set of water parcels:

$$
\Theta_{1}=\sum_{n=1}^{100} \Delta \Theta_{1}\left(x_{0}, y_{0},\left[z_{0}^{(n)}=\left(n-\frac{1}{2}\right) 10 m\right], t_{0}\right) .
$$

As shown in Figure 4, $\Theta_{1}$ is minimum for the east equatorial warm anomaly 11.5 months before the anomaly time, when the horizontally averaged $\Theta_{1}$ was $52.3 \mathrm{~K} \mathrm{~m}$. This first diagnostic term is used as a stopping criterion. We choose our $t_{\text {init }}$ for this feature to be 11.5 months before the anomaly time, since at that time the total heat anomaly is close to zero.

[28] Examples of trajectories into this eastern equatorial anomaly region are shown in Figure 5. The NULL trajectories into the anomaly follow two main pathways into the maximum point of the anomaly, $\left(119^{\circ} \mathrm{W}, 0^{\circ}\right)$ : a curved internal surface pathway in the upper $60-70 \mathrm{~m}$ from north of the equator, and a deeper pathway $(70-160 \mathrm{~m})$ from the western boundary. Between 0 and $60 \mathrm{~m}$, the origin points of the ENSO trajectories are shallower than in the NULL case, bringing warmer water into the eastern equatorial Pacific. This range accounts for $28.7 \%$ of the total anomaly at the maximum point, and the dominant term is the vertical gradient of $T_{N}$ due to this depth difference. At the other horizontal points within this anomaly, the trajectories are similar, with these two pathways seen at most locations and with the western boundary pathway generally deeper than the interior pathway. West of the maximum point, the trajectories come from the western Pacific along the equator at all depths. To the south and east of the maximum point, however, some ENSO trajectories follow an interior pathway from south of the equator, which is seldom seen in the NULL trajectories (Figure 5). This southern interior pathway is seen at the $115^{\circ} \mathrm{W}, 110^{\circ} \mathrm{W}, 105^{\circ} \mathrm{W}, 0.8^{\circ} \mathrm{S}$, and $2^{\circ} \mathrm{S}$ locations in the ENSO trajectories, and is seen only at $0.8^{\circ} \mathrm{S}$ for a few NULL trajectories.

[29] There are therefore three pathways that are important in this eastern equatorial Pacific warm anomaly, the western boundary pathway (WBP), the northern interior pathway (NIP), and the southern interior pathway (SIP). Examples can be seen in Figure 5, and these are shown in schematic form in Figure 6. The two interior pathways are much more active during ENSO than during normal (NULL) times, and
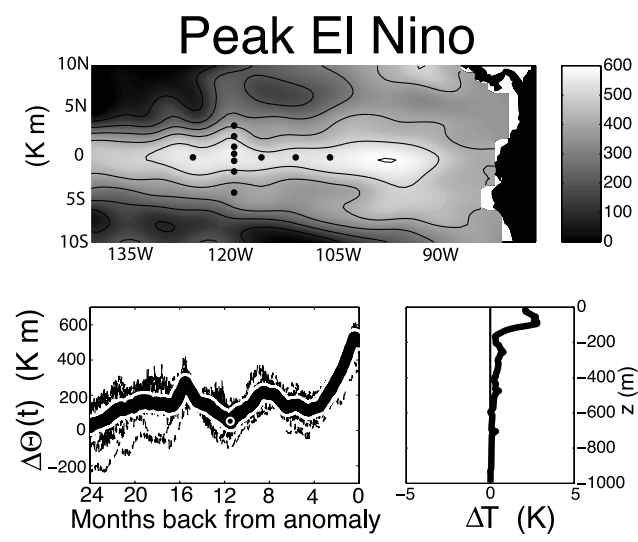

Figure 4. Eastern equatorial warm anomaly at the peak of the ENSO event. (top) Map of the vertically integrated heat content anomaly, in which the black dots indicate the horizontal position of the trajectory computations. Units are Kelvin meters $(\mathrm{K} \mathrm{m})$, and the contour interval is $100 \mathrm{~K} \mathrm{~m}$. (bottom right) Average vertical profile of the temperature anomaly. (bottom left) Time series of the vertically integrated heat content anomaly for each of the 11 horizontal positions, with the time, 11.5 months back, when this is minimized marked with a white circle. 


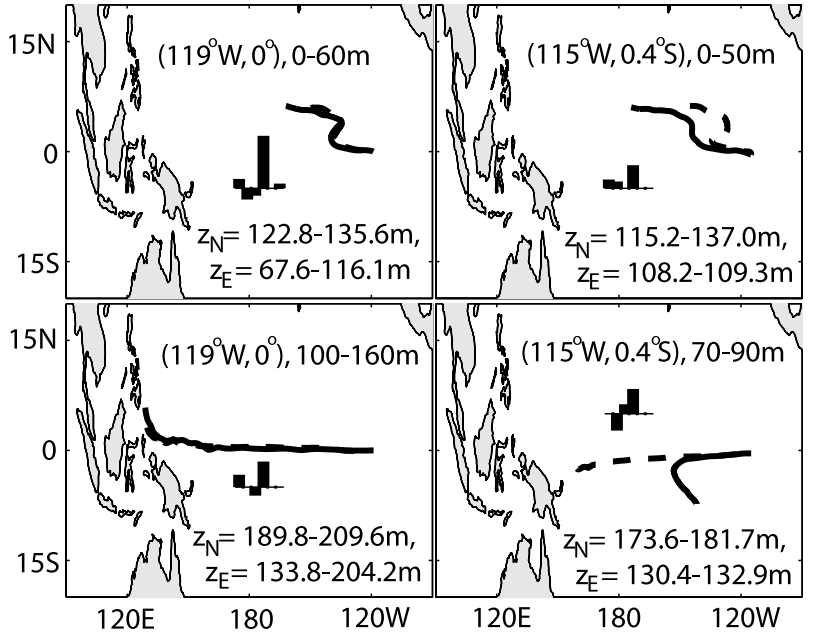

Figure 5. A few of the trajectories for the eastern equatorial warm anomaly at the peak of the ENSO event. (left) Point $119^{\circ} \mathrm{W}, 0^{\circ}$; (right) point $115^{\circ} \mathrm{W}, 0.4^{\circ} \mathrm{S}$. The dashed lines are the NULL median trajectories, and the solid lines are the ENSO median trajectories. Trajectories shown are the median positions of all trajectories in the specified depth range (one for every $10 \mathrm{~m}$ ). The depth ranges are indicated in each panel. The inset bar graph on each panel indicates the relative importance of each of the six diagnostic terms, from left to right. For example, in the top left panel, the fourth term, which is the vertical gradient of the temperature, dominates.

are shifted westward and shallower. The NIP includes 81 trajectories during ENSO, versus 66 for the NULL case, and contributes $25.2 \%$ of the total anomaly. The contribution of just those trajectories that follow the NIP during ENSO but not during NULL accounts for $6.1 \%$ of the total anomaly. The remainder of the NIP contribution to the ENSO anomaly is due to the NIP shifting westward and originating from shallower depths under ENSO conditions. The SIP strengthens significantly during ENSO, from 13 trajectories to 25 . The contribution of the SIP to the total anomaly is $13.1 \%$, and $11.5 \%$ of the total anomaly is due just to those trajectories that follow the SIP during ENSO but not during NULL. The rest of the SIP contribution to the ENSO anomaly is again from the zonal and vertical shift in the pathway origin. The two interior pathways are generally shallower than the WBP, so that parcels which follow the WBP during NULL conditions, but follow the NIP or SIP during ENSO, are anomalously shallow in origin, and therefore anomalously warm, during ENSO events. The remainder of the anomaly is due to trajectories following the WBP, which is also anomalously shallow during ENSO.

[30] The horizontal character of these three pathways is consistent with the flow pattern along isopycnal surfaces between $\sim 50$ and $100 \mathrm{~m}$ of depth in the NCEP reanalysis data [see Zhang and Rothstein, 2000, Figure 3]. The NIP consists of parcels originating between $\sim 5^{\circ} \mathrm{N}$ and $8^{\circ} \mathrm{N}$ and between $160^{\circ} \mathrm{W}$ and $120^{\circ} \mathrm{W}$, and heading southeastward in the North Equatorial Countercurrent (NECC). These parcels then switch to the South Equatorial Current (SEC) to travel southwestward from $\sim 5^{\circ} \mathrm{N}$ to $\sim 2^{\circ} \mathrm{N}$, and finally turn eastward along the equator in the Equatorial Undercurrent
(EUC). The SIP consists of parcels traveling northwest from between $5^{\circ} \mathrm{S}$ and $10^{\circ} \mathrm{S}$ (at $\sim 145^{\circ}-135^{\circ} \mathrm{W}$ for ENSO, or $\sim 125^{\circ} \mathrm{W}$ for the NULL case) in the SEC, and then turning eastward along the equator in the EUC. Like the northern pathway, this pathway is shallower and further west under ENSO conditions than under NULL conditions, so that the water that reaches the anomaly region is warmer than it would otherwise be. The ENSO increase in activity for this pathway is much more striking than the increase in the northern pathway. The WBP simply consists of parcels traveling all the way from the western boundary region in the EUC, upwelling along the path. This pathway is active in both ENSO and NULL conditions. The depth ranges it affects, however, are changed during ENSO as the two interior pathways take over more of the picture. Finally, there are also some effects of the surface heat flux, mainly due to the pathway differences. These contribute only on the northern and southern edges of the anomaly where the magnitude of the anomaly is reduced by $40-50 \%$. Thus the surface heating appears to be relatively unimportant.

\subsection{Off-Equatorial Warming in the Eastern Pacific}

[31] Once the warm anomaly has reached its peak strength in the eastern equatorial Pacific (by month 37), the warming begins to spread north and south along the coast of the Americas. By month 39, two off-equatorial anomalies have formed off the coast, distinct from the equatorial warming, at $10^{\circ}-15^{\circ}$ north and south, as shown in Figure 7. The northern anomaly is stronger than the southern one, and further west. We have chosen to examine trajectories into a set of points surrounding the maximum of each of these anomalies. The average vertical profile of $\left(T_{E}-T_{N}\right)$ of each is also shown in Figure 7. These anomalies have two distinct depth of interest. The first is a

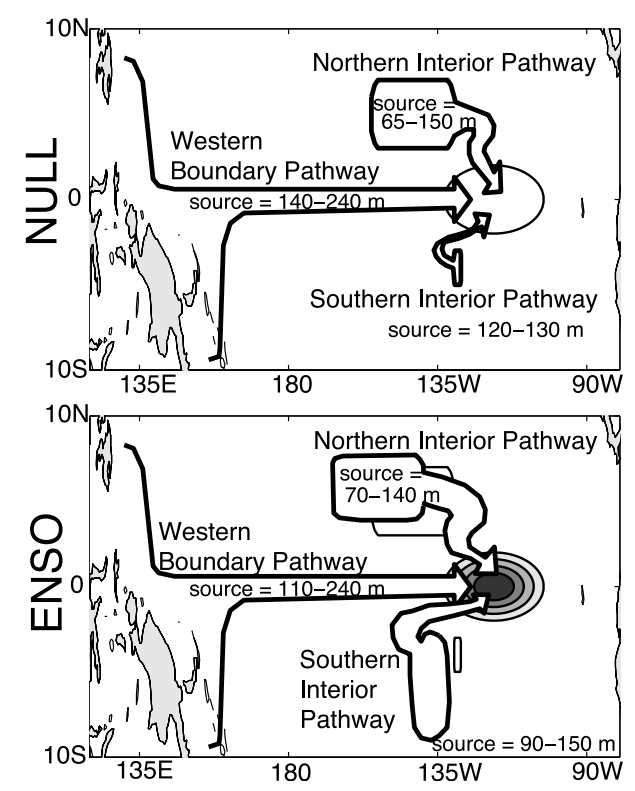

Figure 6. Schematics showing the position and importance of the three major pathways during (top) NULL and (bottom) ENSO conditions. Each is in map view. The depths of origin for each pathway are indicated. In the ENSO subplot the source regions for the NULL case are shown in thinner lines for comparison. 


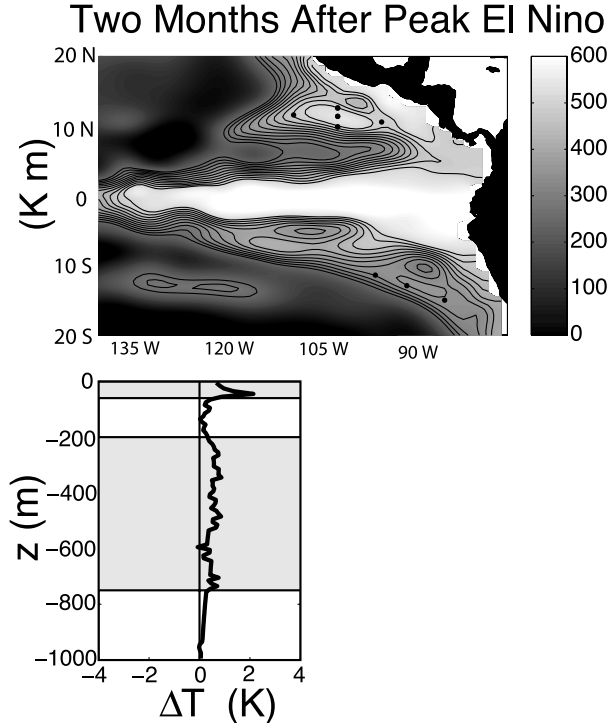

Figure 7. Off-equatorial warm anomalies in the eastern Pacific 2 months after the peak of the ENSO event. (top) Map of the vertically integrated heat content anomaly. The black dots indicate the horizontal locations for which trajectories were computed. Units are $\mathrm{K} \mathrm{m}$, and the contour interval is $25 \mathrm{~K} \mathrm{~m}$. (bottom) Horizontally averaged (over both the northern and southern anomalies) vertical profile, with two depth ranges of interest $(0-60 \mathrm{~m}$ and $200-750 \mathrm{~m})$ highlighted in gray.

strong but thin maximum in approximately the upper $60 \mathrm{~m}$. Most of the anomaly occurs, however, in a weaker but broader peak between $\sim 200 \mathrm{~m}$ and $750 \mathrm{~m}$, which will be discussed in more detail later in this section. At most points in the anomaly, these ranges are separated by a layer $\sim 100 \mathrm{~m}$ thick that is not anomalously warm or cold. West of the maximum, this is actually a layer of anomalously cold water, while east of the maximum this layer is less noticeable. The southern anomaly is weaker, and the water column is more uniformly anomalously warm in the upper $1000 \mathrm{~m}$. The value of the first diagnostic term, $\Theta_{1}$, is minimum at 11 months and 5 days back from the anomaly time, which is, for reference, 9 months and 5 days back from the peak ENSO warm anomaly discussed in the preceding section. This was chosen as the initial time for the trajectories into these off-equatorial anomalies.

[32] We will begin this section by discussing the northern anomaly in some detail, as the southern anomaly is similar in many respects. There is a strong maximum near the surface at all of the horizontal points examined in the northern off-equatorial anomaly. At the maximum point of the anomaly, $102^{\circ} \mathrm{W}$ and $11.4^{\circ} \mathrm{N}$ (see Figure 8), the NULL trajectories in the upper $60 \mathrm{~m}$ come in to the location of the anomaly from due east about $10^{\circ}$ away, while the ENSO trajectories over the same depth range come in from the southwest at about the same distance. The ENSO trajectories travel much farther, first eastward along $7^{\circ}-8^{\circ} \mathrm{N}$ and then turning northwestward just west of $90^{\circ} \mathrm{W}$. The zonal differences in the origin points of the NULL and ENSO trajectories contributes strongly and positively toward the anomaly, but the ENSO trajectories are also deeper than the NULL, which tends to counter the warming. Finally, the surface heating, particularly the pathway effect, contributes to the warming. This depth range is $25.7 \%$ of the local anomaly, or $122.5 \mathrm{~K} \mathrm{~m}$.

[33] As noted in the beginning of this section, the majority of the warming was in the deep water for all horizontal locations, generally between $\sim 200 \mathrm{~m}$ and $750 \mathrm{~m}$, with the largest anomaly between $200 \mathrm{~m}$ and $600 \mathrm{~m}$. Flows are weak at such depths, so neither the ENSO nor the NULL trajectories reflect very much motion in the horizontal. The ENSO trajectories, however, tend to originate at shallower points than the NULL, and the vertical gradient of $T_{N}$ is thus the dominant factor in this warming. In fact, the NULL trajectories in this depth range move very little in the vertical, while the ENSO trajectories over this range tend to move deeper over this time period, with an average depth change of between 15 and $30 \mathrm{~m}$. The range $200-600 \mathrm{~m}$ is responsible for $45.0 \%$ of the anomaly at the maximum point, or $214.5 \mathrm{~K} \mathrm{~m}$. The other horizontal points are similarly dominated by this depth range. The southern anomaly is quite similar to the northern one. As with the northern anomaly, most of the warming comes in at depth, between $200 \mathrm{~m}$ and $600 \mathrm{~m}$. Over half $(51.2 \%)$ of the anomaly at $12.9^{\circ} \mathrm{S}$, or $196.1 \mathrm{~K} \mathrm{~m}$, is due to the vertical temperature gradient term in the $200-600 \mathrm{~m}$ depth range, and the other horizontal points are comparable.

[34] These results, that most of the temperature anomalies occur deep in the water column, below $200 \mathrm{~m}$, for both the northern and southern anomaly regions, and that the vertical temperature gradient term dominates, are indicative of an ENSO downwelling. The horizontal motions at such depths are small. The NULL trajectories in both anomalies upwell
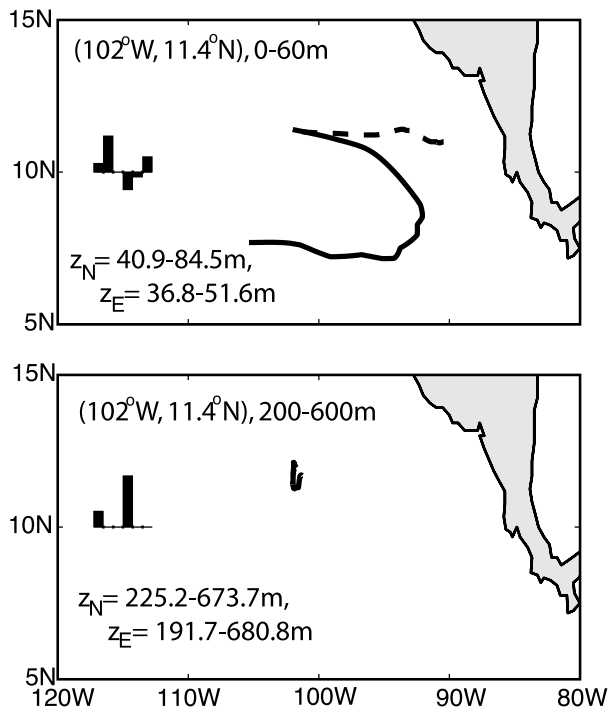

Figure 8. Trajectories for the eastern Pacific off-equatorial anomalies, at $102^{\circ} \mathrm{W}$ and $11.4^{\circ} \mathrm{N}$. (top) Upper $60 \mathrm{~m}$ (six trajectories in group) and (bottom) the deep anomaly, between 200 and $600 \mathrm{~m}$ (40 trajectories in group). The dashed lines are the NULL median trajectories, and the solid lines are the ENSO median trajectories. Trajectories shown are the median positions of all trajectories in the specified depth range. The inset bar graphs again indicate the relative importance of the six diagnostic terms, from left to right. 


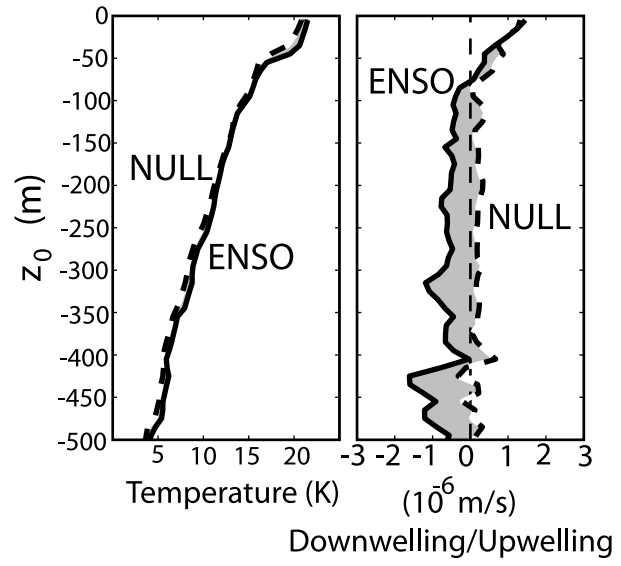

Figure 9. (left) NULL and ENSO vertical temperature profiles of the eastern off-equatorial warm anomalies. The dashed line is the NULL profile, and the solid is the ENSO, while the shading indicates the difference between ENSO and NULL. (right) Downwelling/upwelling experienced by the trajectories indicated as a function of their depth at the time of the anomaly. Again, the dashed line is for NULL, the solid line is for ENSO, and the shading indicates the downwelling/upwelling anomaly.

slightly, while the 200-600 m ENSO trajectories move deeper in the water column (downwelling). This is shown in Figure 9, in which the separate horizontal points have been averaged, using the anomaly strength as a weighting factor. The normal weak upwelling in the region, of $\sim 2 \times$ $10^{-7} \mathrm{~m} / \mathrm{s}$, is replaced by a relatively strong, $\sim 7 \times 10^{-7} \mathrm{~m} / \mathrm{s}$, downwelling during ENSO. We examined this anomalous downwelling using the monthly winds from the National Centers for Environmental Prediction (NCEP), and it cannot be accounted for by variations in the local wind stress curl (Ekman pumping). Rather, it is likely due to wave dynamics.

\subsection{Cool Anomalies in the West Pacific Warm Pool Region}

[35] Shortly after the peak of ENSO warming, the western equatorial Pacific is abnormally cool. This occurs in two cool anomalies at $\sim 5^{\circ}-7^{\circ} \mathrm{N}$ and $4^{\circ}-6^{\circ} \mathrm{S}$, shown in Figure 10, at month 40 ( 3 months after the peak of ENSO). On the basis of our first diagnostic term (13), we have chosen to examine the trajectories entering this anomaly back to just less than five months earlier (two months before the time of the peak warming in the eastern equatorial Pacific).

[36] The depth profiles of the temperature anomalies averaged over the horizontal points within each region at month 40 are also shown in Figure 10. The northern and southern profiles are fairly similar to one another. In each one, most of the cool anomaly is between $\sim 50 \mathrm{~m}$ and $300 \mathrm{~m}$ of depth. At the point of the maximum anomaly and north and west of this point, the ENSO temperatures in the upper water column (approximately the upper $50 \mathrm{~m}$ ) are close to the normal temperatures. To the south and east of the anomaly maximum, there is actually a positive (warm) anomaly in the upper water column, partially balancing the stronger negative (cool) anomaly beneath.
[37] At the maximum amplitude point of the northwestern anomaly $\left(180^{\circ}, 7.3^{\circ} \mathrm{N}\right.$, see Figure 10$)$, the ENSO and NULL trajectories are very similar below $60 \mathrm{~m}$, all coming from nearly due west of the anomaly. Flow is fastest for the 60-170 m depth range trajectories; the trajectories below $170 \mathrm{~m}$ travel very little in the horizontal at all. The ENSO trajectories consistently come from deeper source water than the NULL, however. The vertical temperature gradient term dominates, accounting for most of the anomaly. The anomaly is strongest between 50 and $300 \mathrm{~m}$ for every horizontal position within this (northern) west Pacific cool anomaly, and the vertical temperature gradient term dominates everywhere. The ENSO variations of the horizontal trajectory behavior occur mainly in the near-surface waters, where the anomaly is weak. The southern cool anomaly in the west Pacific is very similar to the northern anomaly described above.

[38] The dominant cause of the cooling in the western Pacific, after the peak of the ENSO warm event, is the degree of upwelling at depths between 50 and $300 \mathrm{~m}$. In this depth range at every location, the dominant term is the effect $\left(\Delta \Theta_{4}\right)$ of the vertical gradient of the NULL temperature combined with the difference in source depth for the NULL and ENSO trajectories. There is some variation in the degree of upwelling from place to place, of course. For

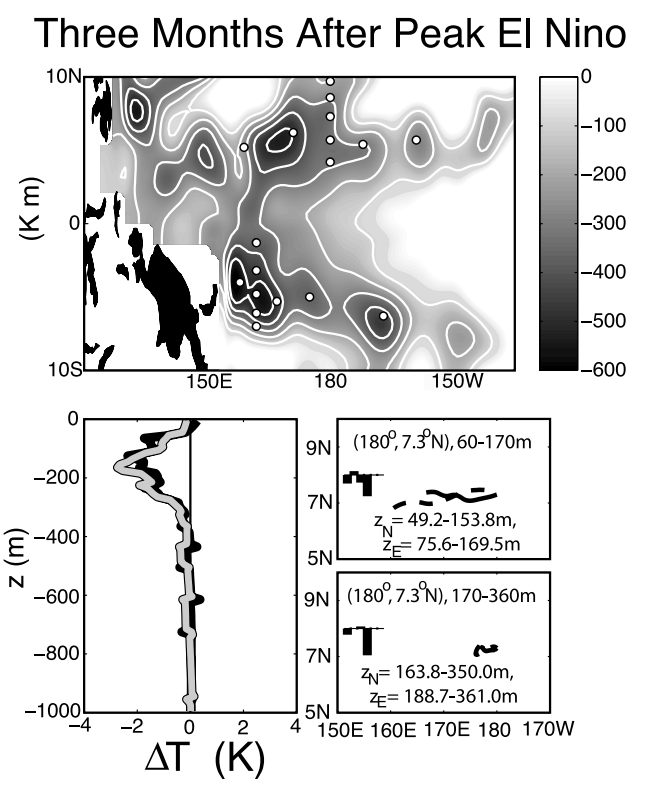

Figure 10. Off-equatorial cool anomalies in the western Pacific. (top) Map of the vertically integrated heat content anomaly, with the white dots indicating the horizontal positions for which trajectories were computed. Units are $\mathrm{K}$ $\mathrm{m}$, and the contour interval is $100 \mathrm{~K} \mathrm{~m}$. (bottom left) Average vertical profile of the temperature anomaly for the northern (black line) and southern (shaded line) regions. (bottom right) Trajectories for the $180^{\circ}, 7.3^{\circ} \mathrm{N}$ point in the northwestern off-equatorial anomaly for the depth ranges $60-170 \mathrm{~m}$ (11 trajectories in group) and $170-360 \mathrm{~m}$ (19 trajectories in group), as labeled. Trajectories shown are the median positions of all trajectories in the specified depth range. The inset bar graphs show the relative importance of the six diagnostic terms, from left to right. 

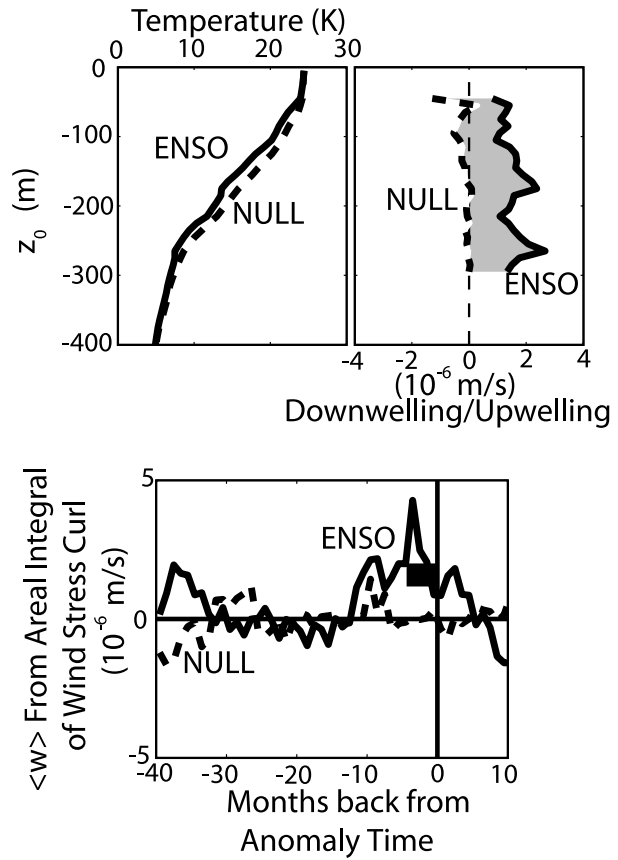

Figure 11. Vertical temperature profile, downwelling/ upwelling, and the Ekman pumping for the off-equatorial cool anomaly regions in the western Pacific. (top left) Temperature profiles and (top right) downwelling/upwelling as a function of the depth of each water parcel at the time of the anomaly. These vertical profiles have been averaged over all the horizontal points in the anomaly regions. The dashed lines are for the NULL case, the solid lines are for the ENSO case, and the shading between these indicates the size of the anomaly. (bottom) Ekman pumping computed from the wind fields used as inputs to the model for the NULL case (dashed line) and the ENSO case (solid line). The solid vertical line shows the time of the anomaly. The bold horizontal line shows the amount of upwelling observed in the trajectories over the several months prior to the anomaly.

instance, at $\left(171^{\circ} \mathrm{E}, 6.2^{\circ} \mathrm{N}\right)$, the ENSO trajectories below $120 \mathrm{~m}$ originate $20-25 \mathrm{~m}$ deeper than the corresponding NULL trajectories. At $\left(162^{\circ} \mathrm{E}, 1.3^{\circ} \mathrm{S}\right)$, the ENSO trajectories between 50 and $80 \mathrm{~m}$ are only a few meters deeper in origin than the NULL, but these few meters are within the thermocline, so the vertical gradient of the temperature again dominates this depth range.

[39] The trajectories computed under ENSO conditions generally originate deeper in the water column than the trajectories computed under NULL (normal) conditions, so that the regions of the anomalies are cooled during ENSO. There are other effects, namely the zonal and meridional gradients of the normal (NULL) temperature, $\Delta \Theta_{2}$ and $\Delta \Theta_{3}$, and the surface heating, particularly in the pathway term $\Delta \Theta_{6}$, but these tend to be important only at the fringes of the anomalies, either horizontally far from the maximum points or in depth ranges (the near surface in particular) that contribute little to the anomaly signal. Figure 11 shows the effect of ENSO upwelling. The profiles have been averaged over all horizontal points in both cool anomalies, using anomaly strength as a weighting factor. The temper- ature profiles on the left of the figure demonstrate that the anomalies are strongest around the thermocline. From the upwelling/downwelling profiles on the right side of the figure we can see that, while under NULL conditions there is very little vertical motion, there is strong upwelling (15$20 \mathrm{~m}$ over approximately 5 months, or $10-13 \mathrm{~cm} /$ day) during ENSO throughout the depth range of the maximum anomaly.

[40] The anomalous upwelling in these regions during ENSO can be accounted for in turn by anomalies in the curl of the local wind stress. The Ekman pumping, or upwelling/ downwelling caused by the wind stress curl, is given by

$$
w=\frac{1}{\rho} \hat{k} \cdot\left(\nabla \times \frac{\tilde{\tau}}{f}\right),
$$

where $\mathrm{w}$ is the vertical velocity, $\rho$ is the density, $\hat{k}$ is a vertical unit vector, $\tilde{\tau}$ is the wind stress, and $f$ is the Coriolis parameter. Using Stokes theorem, the average of this Ekman pumping over a geographic region can be written as

$$
\langle w\rangle=\frac{1}{\rho A} \oint_{c} \frac{\tilde{\tau}}{f} \cdot d \tilde{r},
$$

where the integral is taken around a closed boundary. This was computed for two boxes within the western Pacific cool anomalies, $170^{\circ} \mathrm{E}-170^{\circ} \mathrm{W}, 5^{\circ}-7^{\circ} \mathrm{N}$ and $160^{\circ}-180^{\circ} \mathrm{E}, 6^{\circ}-$ $4^{\circ} \mathrm{S}$. The results are shown in Figure 11. There is little Ekman upwelling or downwelling in the NULL case, while the ENSO winds produce strong upwelling for several months prior to the peak of the cool anomalies, sufficient to explain the upwelling and cooling in those regions.

\section{Discussion}

[41] All of the preceding discussion about pathways in this paper has concerned a composite ENSO warm event, composed of four separate events. We recognize that there can be a great deal of variation between one warm event and another, but for the present study we have chosen to examine the dynamics of a typical ENSO warm event via this compositing method. The strongest of the four included events was the 1997 event, which is in fact the largest amplitude ENSO warm event on record. It is therefore logical to expect that the composite should resemble this event, since no artificial weighting was introduced in the averaging of the events. Indeed, the vertically integrated heat content at the peak warming of the composite (month 37 ) is quite comparable to the heat content in September 1997, where the long-term mean and the mean seasonal cycle have been removed. The vertical profiles of the temperature anomaly are also quite similar, although the 1997 event is much stronger than the composite and appears to have a larger portion of the heat content anomaly below the surface waters (near the secondary peak at $\sim 200$ $250 \mathrm{~m}$ ). When trajectories were computed, the three major pathways (NIP, SIP, and WBP) contributed similarly in the composite and the 1997 event, in terms of both number of trajectories and anomaly contribution in $\mathrm{K} \mathrm{m}$. The biggest difference is in the trajectories following the western boundary pathway for both NULL and ENSO, where the 
number of trajectories drops slightly from the composite to the 1997 event, but the anomaly contribution (in $\mathrm{K} \mathrm{m}$ ) nearly doubles. Finally, the diagnostic terms are also similar between the composite ENSO warm event and the 1997 event. The vertical temperature gradient term dominates in the upper $350 \mathrm{~m}$, with secondary contributions (in both the composite and 1997) in the upper $200 \mathrm{~m}$ from the zonal temperature gradient and the pathway effect of the surface heat flux. Below $350 \mathrm{~m}$, the initial anomaly term dominates, indicating that the causes of the anomaly are not well resolved, but the anomaly is quite small at such depths. Examining the pathways and processes of other individual ENSO events is beyond the scope of this paper, but we do expect that there may be important differences, and this is an area where future work is needed.

[42] In addition, the fact that changes in vertical position can be such an important part of the development and progression of ENSO events (particularly the west Pacific off-equatorial upwelling) suggests that the manner in which a numerical model simulates the vertical mixing, and in particular how the mixed layer is treated, could have important consequences for the interpretation of ENSO dynamics. Several runs of the Gent and Cane [1989] model were completed as part of this study, with a variety of mixed layer dynamics. The standard run, which has been the subject of all discussion in this paper up to this point, uses the Chen et al. [1994] vertical mixing scheme, which incorporates shear instability, convection, and wind-induced mixing. The degree to which the wind contributes to the mixing is set by a tunable parameter, $\mathrm{c}_{\mathrm{m}}$. In the standard run, this is set to 1.25 . For the purpose of comparisons, runs were completed using the same mixing scheme with this parameter set to half (0.6) and double (2.5) its value in the standard run. In addition, a fourth run was done with relatively simplistic mixed layer dynamics, in which the depth of the mixed layer was fixed at $50 \mathrm{~m}$ at all locations and all times. There is higher variability in the three mixed layer comparison runs at the peak month of ENSO than in the standard run, but there is good overall agreement. The low wind mixing, high wind mixing, and constant mixed layer depth runs are correlated to the standard run (at month 37 over the tropical Pacific, $20^{\circ} \mathrm{S}-20^{\circ} \mathrm{N}$ ) at $0.95,0.95$, and 0.93 , respectively, and the ratio of the standard deviation to that of the standard run ranges between 1.05 and 1.12. The eastern equatorial warm anomaly is present, and is the dominant feature at this time, in all four cases. The temporal evolution of the temperature anomaly for each water parcel is also similar, and the vertical structure is fairly robust in all of the mixed layer comparison runs, with the anomaly largely concentrated in the upper $150 \mathrm{~m}$, but with a second smaller maximum between 150 and $450 \mathrm{~m}$. The relative importance of the pathways is remarkably uniform between the different model runs. In addition, the contributions of the various diagnostic terms to the anomaly are consistent from one model run to another.

[43] All four of the model runs with varying mixing formulations also reproduce the off-equatorial cool anomalies in the western Pacific a few months later. For the tropical Pacific as a whole $\left(20^{\circ} \mathrm{S}-20^{\circ} \mathrm{N}\right)$ at month 40 , the vertically integrated fields of heat content for the $c_{m}=0.6$, $c_{m}=2.5$, and constant mixed layer depth model runs are all correlated to comparable field for the standard model run at
0.94, and the ratios of their standard deviations to that of the standard runs are $0.97,0.90$, and 1.01 respectively. The temporal evolution of both cool anomalies is similar in the four model runs. As was the case for the standard run, in the mixed layer comparison runs these cool anomalies arise almost solely due to the vertical temperature gradient term, because of strong anomalous upwelling in this region during ENSO, as was found by Wang and Weisberg [1999]. The terms leading to the anomaly in each of these $100 \mathrm{~m}$ depth bins are highly correlated between the mixed layer comparison runs and the standard run. The correlation is 0.98 or better between all mixed layer comparison runs and the standard run for the two depth bins, 100-200 $\mathrm{m}$ and 200-300 m, that together account for $70 \%$ or more of the total anomaly, and falls off some above and below the main depth range of the anomaly. We therefore feel confident that the results presented in this paper are robust to changes in the numerical treatment of vertical mixing and the mixed layer.

\section{Summary and Conclusions}

[44] Virtual Lagrangian tracers were inserted into the output fields of the numerical model to diagnose the three-dimensional pathways responsible for the development of a series of anomalies throughout the composite ENSO warm event. These trajectories were run backward in time from the anomaly regions and the temperatures and vertical positions were computed at each time step according to the model velocities and vertical heating fields encountered. Trajectories were run using both NULL and ENSO composite fields for comparison purposes. Each trajectory was evaluated in terms of the contribution it made to the vertically integrated anomaly and its dynamics. The dynamics were diagnosed as being related to the gradients in the temperature field and the zonal, meridional, and vertical differences in ENSO and NULL trajectory origin points, the difference between the ENSO and NULL surface heating fields, or the effect of the trajectory location on the surface heating felt by the water parcel.

[45] A few months before the peak of the ENSO warm event, warm water builds up in the western equatorial and off-equatorial Pacific via the SEC, the EUC, and local downwelling, forming a warm anomaly in the central west Pacific at month 34 (where the ENSO peak is month 37). Between months 34 and 37, this anomaly propagates rapidly eastward along the equator, consolidates, and is strengthened by three main pathways. The first is the western boundary pathway (WBP), which is essentially the EUC once the parcels have traveled along the western boundary and reached the equatorial zone. This pathway is shallower during the ENSO warm event, which brings anomalously warm water into the anomaly region as it moves eastward. In addition, there are two interior pathways to the anomaly, the northern (NIP) and southern (SIP) interior pathways. Both of these can be seen in the NCEP reanalysis data [see Zhang and Rothstein, 2000, Figure 3]. Both of these interior pathways exist under NULL conditions as well, but are strengthened and shifted westward and closer to the surface during the ENSO warm event. These factors cause anomalously warm water to be brought into the eastern equatorial warm anomaly region and are important in the creation and 
strengthening of this anomaly. The eastern equatorial warm anomaly at peak ENSO warming and the dynamics that form it are robust to changes in the mixed layer dynamics of the model.

[46] Two months after the peak in the eastern equatorial zone, warm anomalies are seen off the equator, at $10^{\circ} \mathrm{N}$ and $10^{\circ} \mathrm{S}$. Most of the anomalous temperatures are deep in the water column, between $\sim 200$ and $600 \mathrm{~m}$. The dominant factor in causing these anomalies is anomalous local downwelling, consistent with the reflection of downwelling Rossby waves off of the coasts of North and South America.

[47] Vertical displacements are also of primary importance in the western equatorial Pacific, where two cool anomalies form 3 months after the peak of ENSO at $\sim 5^{\circ}$ north and south of the equator. The ENSO and NULL trajectories into the anomaly regions are horizontally very similar. In fact, most of the anomaly occurs deeper in the water column (between 50 and $300 \mathrm{~m}$ ), where the horizontal transports are relatively small. This depth range is situated about the thermocline and the vertical temperature gradient term dominates all of the other diagnostic terms at every horizontal point examined. The cooling is due to strong upwelling in these regions during ENSO events. This anomalous upwelling during ENSO can be attributed to local Ekman pumping anomalies.

[48] Acknowledgments. This work was supported by NASA and the Jet Propulsion Laboratory as part of the TOPEX Altimeter Research in Ocean Circulation and the JASON-1 project. C. Holland was partially supported by a NASA Earth System Science Fellowship, the University of South Florida, the College of Marine Science, and the St. Petersburg community. We thank R. Murtugudde, A. Busalacchi, R. Weisberg, M. Luther, and F. Muller-Karger for many helpful discussions.

\section{References}

Bjerknes, J. (1969), Atmospheric telecommunications from the equatorial Pacific, Mon. Weather Rev., 97, 163-172.

Cane, M. A. (1983), Oceanographic events during El Niño, Science, 222, $1189-1195$

Cane, M. A., and S. E. Zebiak (1985), A theory for El Niño and the Southern Oscillation, Science, 228, 1084-1087.

Chen, D., L. M. Rothstein, and A. J. Busalacchi (1994), A hybrid vertical mixing scheme and its implication to tropical ocean models, J. Phys. Oceanogr., 24, 2156-2179.

Coles, V. J., and M. M. Rienecker (2001), North Pacific subtropical-tropical gyre exchanges in the thermocline: Simulations with two isopycnic OGCMs, J. Phys. Oceanogr., 31, 2590-2611.

Fukimori, I., T. Lee, B. Chang, and D. Menemenlis (2004), The origin, pathway, and destination of Niño-3 water estimated by a simulated passive tracer and its adjoint, J. Phys. Oceanogr., 24, 582-604.

Gent, P. G., and M. A. Cane (1989), A reduced gravity, primitive equation model of the upper equatorial ocean, J. Comput. Phys., 81, $444-480$.

Gill, A. E. (1980), Some simple solutions for heat-induced tropical circulation, Q. J. R. Meteorol. Soc., 106, 447-462.

Holland, C. L., and G. T. Mitchum (2003), Interannual volume variability in the tropical Pacific, J. Geophys. Res., 108(C11), 3369, doi:10.1029/ 2003JC001835.

Huang, R. X., and Q. Wang (2001), Interior communication from the subtropical to the tropical oceans, J. Phys. Oceanogr., 31, 3538-3550.

Izumo, T., J. Picaut, and B. Blanke (2002), Tropical pathways, equatorial undercurrent variability and the 1998 La Niña, Geophys. Res. Lett., 29(22), 2080, doi:10.1029/2002GL015073.

Jin, F.-F. (1997a), An equatorial ocean recharge paradigm for ENSO. part I: Conceptual model, J. Atmos. Sci., 54, 811-829.

Jin, F.-F. (1997b), An equatorial ocean recharge paradigm for ENSO. part II: A stripped down coupled model, J. Atmos. Sci., 54, 830-847.

Johnson, G. C., and M. J. McPhaden (1999), Interior pycnocline flow from the subtropical to the equatorial Pacific Ocean, J. Phys. Oceanogr., 29, $3073-3089$.
Liu, Z. (1994), A simple model of the mass exchange between the subtropical and tropical ocean, J. Phys. Oceanogr., 24, 1153-1165.

Liu, Z., S. G. H. Philander, and R. C. Pacanowski (1994), A GCM study of tropical-subtropical upper-ocean water exchange, J. Phys. Oceanogr., 24, $2606-2623$

Lu, P., and J. P. McCreary (1995), Influence of the ITCZ on the flow of thermocline water from the subtropical to the equatorial Pacific Ocean, J. Phys. Oceanogr., 25, 3076-3088.

McPhaden, M. J., and R. A. Fine (1988), A dynamical interpretation of the tritium maximum in the central equatorial Pacific, J. Phys. Oceanogr., 18, $1454-1457$

McPhaden, M. J., and D. Zhang (2002), Slowdown of the meridional overturning circulation in the upper Pacific Ocean, Nature, 415, 603-608.

Meinen, C. S., and M. J. McPhaden (2000), Observations of warm water volume changes in the equatorial Pacific and their relationship to El Niño and La Niña, J. Clim., 13, 3551-3559.

Miller, L., and R. Cheney (1990), Large-scale meridional transport in the tropical Pacific Ocean during the 1986-1987 El Niño from Geosat, J. Geophys. Res., 95, 17,905-17,919.

Mitchum, G. T. (1987), Trade-wind fluctuations associated with El NiñoSouthern Oscillation events, J. Geophys. Res., 92, 9464-9468.

Murtugudde, R., and A. J. Busalacchi (1998), Salinity effects in a tropical ocean model, J. Geophys. Res., 103, 3283-3300.

Murtugudde, R., R. Seager, and A. J. Busalacchi (1996), Simulation of the tropical oceans with an ocean GCM coupled to an atmospheric mixedlayer model, J. Clim., 9, 1795-1815.

Nonaka, M., and S.-P. Xie (2000), Propagation of North Pacific interdecadal subsurface temperature anomalies in an ocean GCM, Geophys. Res. Lett., 27, 3747-3750.

Perigaud, C., S. E. Zebiak, F. Melin, J.-P. Boulanger, and B. Dewitte (1997), On the role of meridional wind anomalies in a coupled model of ENSO, J. Clim., 10, 761-773.

Picaut, J, M. Ioualalen, C. Menkes, T. Delcroix, and M. J. McPhaden (1996), Mechanism of the zonal displacements of the Pacific warm pool: Implications for ENSO, Science, 274, 1486-1489.

Picaut, J., F. Masia, and Y. du Penhoat (1997), An advective-reflective conceptual model for the oscillary nature of the ENSO, Science, 277, $663-666$.

Rothstein, L. M., R.-H. Zhang, A. J. Busalacchi, and D. Chen (1998), A numerical simulation of the mean water pathways in the subtropical and tropical Pacific Ocean, J. Phys. Oceanogr., 28, 322-343.

Schneider, N., S. Venzke, A. J. Miller, D. W. Pierce, T. P. Barnett, C. Deser, and M. Latif (1999), Pacific thermocline bridge revisited, Geophys. Res. Lett., 26, 1329-1332.

Schopf, P. S., and D. E. Harrison (1983), On equatorial waves and El Niño. I: Influence of initial states on wave-induced currents and warming, J. Phys. Oceanogr., 13, 936-948.

Schopf, P. S., and M. J. Suarez (1988), Vacillations in a coupled oceanatmosphere model, J. Atmos. Sci., 45, 549-566.

Schopf, P. S., and M. J. Suarez (1990), Ocean wave dynamics and the time scale of ENSO, J. Phys. Oceanogr., 20, 629-645.

Seager, R., and R. Murtugudde (1997), Ocean dynamics, thermocline adjustment, and regulation of tropical SST, J. Clim., 10, 521-534.

Springer, S. R., M. J. McPhaden, and A. J. Busalacchi (1990), Oceanic heat content variability in the tropical Pacific during the 1982-1983 El Niño, J. Geophys. Res., 95, 22,089-22,101.

Wang, C. (2001), A unified oscillator model for the El Niño-Southern Oscillation, J. Clim., 14, 98-115.

Wang, C., and R. H. Weisberg (1999), Western Pacific interannual variability associated with the El Niño-Southern Oscillation, J. Geophys. Res., 104, 5131-5149.

Weisberg, R. H., and C. Wang (1997), A western Pacific oscillator paradigm for the El Niño-Southern Oscillation, Geophys. Res. Lett., 24, 779-782.

Wyrtki, K. (1975), El Niño-The dynamics response of the equatorial Pacific to atmospheric forcing, J. Phys. Oceanogr, 5, 572-584.

Wyrtki, K. (1985), Water displacements in the Pacific and the genesis of El Niño cycles, J. Geophys. Res., 90, 7129-7132.

Zhang, R.-H., and L. M. Rothstein (2000), Role of off-equatorial subsurface anomalies in initiating the 1991-1992 El Niño as revealed by the National Centers for Environmental Prediction ocean reanalysis data, J. Geophys. Res., 105, 6327-6339.

C. L. Holland, Institute for Geophysics, University of Texas, 4412 Spicewood Springs Road \#600, Austin, TX 78759, USA. (cholland@utig. ig.utexas.edu)

G. T. Mitchum, College of Marine Science, University of South Florida, 140 Seventh Avenue South, St. Petersburg, FL 33701, USA. (mitchum@ seas.marine.usf.edu) 